\title{
Cooperative and Autonomous Control Strategy of AC Microgrid with Energy Storage System
}

\author{
Myeong-Jun Jang ${ }^{1}$ and Kyeong-Hwa Kim ${ }^{2}$ \\ ${ }^{1,2}$, Department of Electrical and Information Engineering \\ Seoul National University of Science and Technology \\ 232 Gongneung-ro, Nowon-gu, Seoul, 01811, Korea \\ ${ }^{2}$ Corresponding Author \\ E-mail:k2h1@seoultech.ac.kr
}

\begin{abstract}
As the penetration of renewable energy resources such as the solar and wind power (WP) generation is rapidly expanded into the electrical grid, microgrid which is generally composed of multiple distributed generations (DGs), local loads, and energy storage systems (ESSs) becomes increasingly important. In particular, ESS can significantly contribute to manage unstable and intermittent renewable energy sources in microgrid. In this paper, a cooperative and autonomous control strategy for AC microgrid and its operation algorithms are presented either in grid-connected or islanded mode. For a coordinated operation of DG unit in the electrical network, microgrid operation algorithms and the power flow within microgrid are determined according to the generated power from DG unit, the power demand of load, and the ESS status. Also, to implement the operation algorithm of microgrid, the control method for power electronic converters are presented. The entire operation algorithm consists of eight operating modes which include grid-connected or islanded modes. By using the proposed control strategy, microgrid can autonomously and reliably change the operation mode in accordance with the power supply and load demand as well as ESS status. To verify the effectiveness of the proposed operation strategy, integrated simulation studies have been carried out using the PSIM software in which a permanent magnet synchronous generator (PMSG)-based WP generation system and a lithium-ion battery constitute microgrid. Through detailed analysis and simulations results in various operating conditions, it is proved that the proposed microgrid operation algorithm is very useful to improve the flexibility and reliability of the electrical power system as well as to construct cooperative and autonomous microgrid.
\end{abstract}

Keywords: Cooperative and autonomous control, Energy storage system, Gridconnected inverter, Microgrid, Power flow

\section{Introduction}

In recent years, there have been increased interests on the development of renewable energy sources because of the critical worldwide energy situation caused by the depletion of fossil fuel and the greenhouse gas emission limit. The recent development trend constructing electrical power grid is to share distributed generation (DG) units with electrical power systems, which has a significant impact on the operation of electric distribution networks [1]. As the penetration of DG systems into electrical power grid is accelerated rapidly, an innovative concept of microgrid began to emerge. Since microgrid is normally composed of multiple DGs, local loads, and energy storage systems (ESSs), this demands a coordinated operating approach to integrate multiple DG units in the network, which allows DG units to actively contribute to frequency and voltage regulation. Also, microgrid can provide more technical benefits and control flexibilities to 
utility grid as compared with the conventional electrical power system [2]. The essential functionality of microgrids is to have the ability to operate either in grid-connected or islanded mode in case of the absence of the main grid. Another requirement is to handle effectively the exchange of active and reactive power between the microgrid and main grid [3]. In order to meet these requirements, the control strategy of microgrid is generally designed based on three levels of hierarchical structure such as the primary control, secondary control, and tertiary control, which provides smartness and flexibility to microgrid [4].

Microgrids can provide benefits for both utility and microgrid participants [1]. It gives benefits of scale for the utility, and moreover, it can deliver the power with better power quality and high reliability for consumers. Typical configuration of microgrid which operates at low voltage distribution has ESS as well as various distributed energy resources such as solar panels and wind turbines. Microgrid is electrically connected at the point of common coupling (PCC) to connect to the low voltage network in which each component operates in parallel with utility grid under normal situations [5]. Microgrid is linked to utility grid through a grid-connected inverter which is generally operates in bidirectional mode to transfer the power from microgrid to main grid or in the opposite direction. When the fault occurrences appear in the main power grid, microgrid is disconnected and operates in an islanded mode. Islanded mode is the mode in which microgrid is disconnected from the main power grid [5]. In islanded mode, the ESS is used to supply the power to local loads within microgrid with the balance between energy generation and consumption especially during islanded operation.

The recent trend to overcome the limitation of DG units in constructing microgrid is to combine ESS for a stability improvement in local power system supplying distributed loads. The ESS provides a very flexible power usage and effective operation of power system. As the sensitive loads and critical loads grows consistently, there has been an increased attempt to work microgrid as an uninterrupted power supply (UPS) system [6]. Moreover, it is very common nowadays that microgrid has sensitive loads in some places such as manufacturing industry or hospital. Also, microgrid power balancing can be ensured by ESS units capable of providing fast power compensation [7]. For this reason, a number of related researches regarding on ESS technologies have been studied, which include the bidirectional power conversion system, battery management system, battery scheduling technique, and estimation scheme of battery state of charge (SOC) [8]-[11]. Also, the researches on seamless transfer have been conducted for seamless mode change between the grid-connected mode to islanded mode [12].

As the integration of DG expands to electrical network, recent researches on microgrids have been focused on the areas such as the demand response, energy efficiency, and load-management programming, which are key requirements of future electrical power system. Microgrid technology has been evolved based on the hierarchical control architecture such as the primary control, secondary control, and tertiary control [1]. In the primary control level, various studies such as a voltage control scheme and a proper power sharing between multiple DG units have been investigated. Energy management systems and optimization in microgrid operation have been studied in the secondary and tertiary control levels. In order to achieve a high power quality of microgrid, lots of research works of DG units on the power quality improvement scheme under harmonicdistorted or unbalanced condition have been investigated.

This paper proposes a cooperative and autonomous control strategy for AC microgrid and its operation algorithm when microgrid is connected with DG unit, local loads, and ESS either in grid-connected or islanded mode. In a grid-connected mode, microgrid should control the active and reactive powers to grid by maintaining the synchronization to grid while supplying the power to local loads. Even in an islanded mode, microgrid should be able to supply the power to local loads continuously by controlling three-phase output voltages in the grid-connected inverter. Microgrid operation algorithms and the 
power flow within microgrid are determined according to the generated power from DG unit, the power demand of load, and the SOC level of battery. In this paper, the operation algorithm and control method for power electronic converters are presented for microgrid connecting a wind power (WP) generation system, ESS, and local loads. The entire operation algorithm consists of eight operating modes which include grid-connected or islanded modes. In each mode, the power flow in microgrid and the control methods for power electronic converters are presented. By using the proposed control strategy, microgrid can autonomously and reliably change the operation mode in accordance with the power supply and load demand as well as ESS status. To verify the effectiveness of the proposed scheme, integrated simulation studies have been carried out using the PSIM software where a permanent magnet synchronous generator (PMSG)-based WP generation system and a lithium-ion battery constitute microgrid. As power electronic interface, three-phase converter, a grid-connected inverter, and bidirectional DC-DC converter are employed. Through detailed analysis and simulations results in various operating conditions, it is proved that the proposed microgrid operation algorithm is very useful to improve the flexibility and reliability of the electrical power system as well as to construct cooperative and autonomous microgrid.

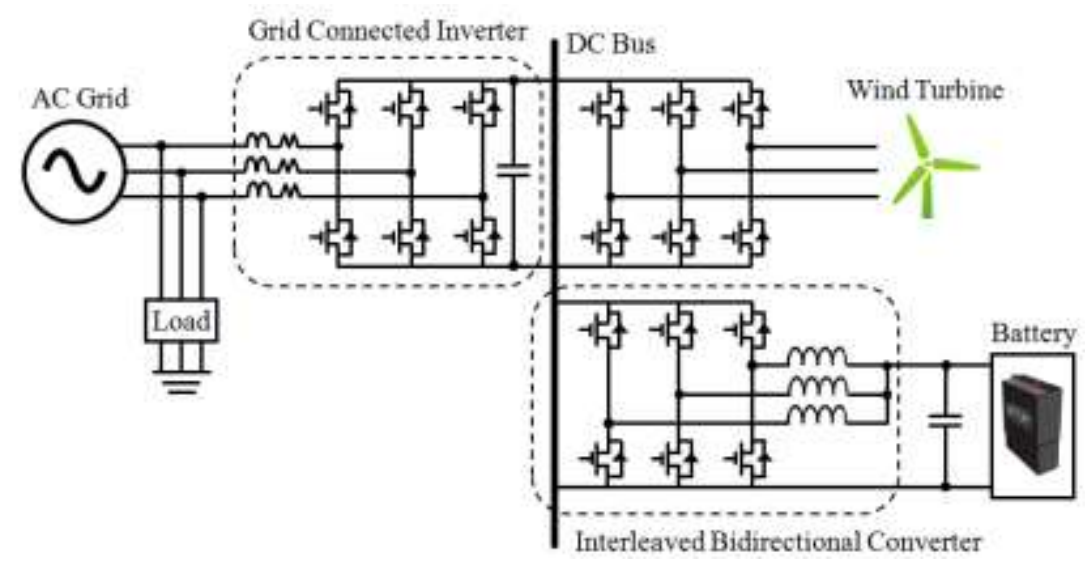

Figure 1. Microgrid Connected with a WP System and ESS

\section{Configuration of AC Microgrid}

Figure 1 shows the configuration of microgrid connected with a WP generation system, ESS, and local load. Due to high efficiency and reduced mechanical stress, a variablespeed WP generation is commonly employed recently. In the variable-speed system, a back-to-back converter composed of a three-phase voltage source converter and a gridconnected inverter is located between the generator and grid, which converts the generator output power in variable voltage and variable frequency to the fixed voltage and frequency of the grid [13]. As a generator, PMSGs are widely employed because they have the advantages such as a simple structure, high efficiency, wide operating range, and no loss in field windings.

In a WP system, the kinetic energy of the wind develops mechanical torque into the PMSG, which is then converted into the electric energy through the back-to-back converter to supply the grid or local load in microgrid. While three-phase voltage source converter regulates the speed of the PMSG to draw the maximum power from the wind turbine, the grid-connected inverter plays a role of transferring active/reactive powers to the grid.

In view of energy flow, three-phase voltage source converter has unidirectional power flow because it only delivers the generated power by a WP system into the DC link. On 
the other hand, the grid-connected inverter has bidirectional power flow according to the power demand in microgrid. When the generated power by the WP system is sufficient, it acts as a grid-connected mode to deliver the surplus power to the grid or local load. It can also be operated as converter mode to charge ESS when the WP system does not produce sufficient power and ESS has a low SOC value.

Another essential component consisting of microgrid is the ESS and power electronic converters to charge/discharge the ESS. Since the electric power generated by renewable energy resources generally has unstable and intermittent nature, the ESS has been widely introduced to mitigate energy fluctuations in microgrid. The power balance between the supply and demand is one of the most important requirements in management of microgrid. Microgrid can operate both in grid-connected and in islanded mode. While microgrid exchanges power to the grid in the grid-connected mode, it should meet the power balance between the generation and load demand in the islanded mode [2]. By installing the ESS on microgrid which commonly consists of renewable energy resources with relatively slow dynamics, microgrid can operate in a stable way even during islanded mode. Moreover, the grid integration and service continuity of electric power system can be improved than ever.

\subsection{Three-Phase Voltage Source Converter}

The model of three-phase voltage source converter coupled with the PMSG is expressed in the synchronous reference frame as follows [14]:

$$
\begin{aligned}
& e_{1 q}=\left(R_{s}+p L_{q}\right) i_{q c}+\omega_{r} L_{d} i_{d c}+v_{q c} \\
& e_{1 d}=\left(R_{s}+p L_{d}\right) i_{d c}-\omega_{r} L_{q} i_{q c}+v_{d c}
\end{aligned}
$$

where subscript " $c$ " denotes the variables in three-phase converter, subscript " $q$ " and " $d$ " denote the $q$-axis and $d$-axis, respectively, $v$ represents the converter voltage, $i$ represents the converter current, $e_{1}$ represents the generated voltage, $R_{s}$ is the resistance, $L_{q}$ and $L_{d}$ are the $q$-axis and $d$-axis inductances of the converter and PMSG, respectively, $\omega_{r}$ is the electrical angular velocity of the generator, and $p$ is a differential operator.

The speed and torque controllers of the PMSG are generally implemented such that the maximum power is extracted from the wind turbine by generating the proper current references. The current controller is accomplished on the synchronous reference frame. With the PI decoupling current control, the voltage references of three-phase converter are calculated as follows:

$$
\begin{gathered}
v_{q c}^{*}=-\left(k_{p c}+\frac{k_{i c}}{s}\right)\left(i_{q c}^{*}-i_{q c}\right)-\omega_{r} L_{d} i_{d c}+e_{1 q} \\
v_{d c}^{*}=-\left(k_{p c}+\frac{k_{i c}}{s}\right)\left(i_{d c}^{*}-i_{d c}\right)-\omega_{r} L_{q} i_{q c}
\end{gathered}
$$

where the symbol "**" denotes the reference quantity, $k_{p c}$ and $k_{i c}$ represent the proportional and integral gains, respectively, and $s$ is the Laplace operator. In threephase converter, the $q$-axis and $d$-axis components of the current control the generator torque and power factor, respectively, and the computed voltage references are applied through the symmetrical space vector PWM technique. When (3) and (4) are applied to the voltage equations in (1) and (2), the transfer function can be obtained as

$$
T(s)=\frac{k_{p c} s+k_{i c}}{L_{q} s^{2}+\left(R_{s}+k_{p c}\right) s+k_{i c}} .
$$


From the second-order transfer function in (5), the current controller bandwidth $\omega_{B}$ can be approximately determined using the damping ratio $\xi$ and natural frequency $\omega_{n}$ as [15]

$$
\omega_{B}=(-1.196 \xi+1.85) \omega_{n} \text { for } 0.3 \leq \xi \leq 0.8 .
$$

\subsection{Three-Phase Grid-Connected Inverter}

In microgrid connecting multiple renewable energy resources such as a solar and WP generation system, the developed powers from different resources are assembled on the DC link bus as shown in Figure 1. The grid-connected inverter delivers the collected powers in the DC link to the grid by controlling the inverter output current. Gridconnected inverters should control the active and reactive powers while maintaining the synchronization to grid frequency for a grid connection. When the grid-connected inverter is employed in microgrid to deliver the generated electrical energy to grid, it should regulate the DC link voltage in order to maintain the power balance of the system. To ensure effective power exchange, the inverter should be operated with high performance in the sense of a fast dynamic response, robustness to disturbance, and zero tracking error. In addition, the grid-connected inverter should able to not only provide stable operation but also improve the system performance even during the presence of abnormal grid conditions to meet the requirement of microgrid.

In the synchronously rotating reference frame, the mathematical model of three-phase grid-connected inverter can be expressed as follows:

$$
\begin{aligned}
& v_{q i}=(R+p L) i_{q i}+\omega L i_{d i}+e_{2 q} \\
& v_{d i}=(R+p L) i_{d i}-\omega L i_{q i}+e_{2 d}
\end{aligned}
$$

where subscript " $i$ " denotes the variables in the grid-connected inverter, $v$ represents the inverter voltage, $i$ represents the inverter current, $e_{2}$ represents the grid voltages, $R$ and $L$ represent the equivalent resistance and inductance of the ac filter and connection cables, respectively, and $\omega$ is the angular frequency of the grid voltage.

When the input power to the DC link becomes larger than the output power to grid, the DC link voltage is increased, and in the opposite case, the DC link voltage is decreased. By controlling the DC link voltage at constant, the grid-connected inverter can deliver the power from the renewable energy resources to the grid. For this purpose, an outer-loop DC link voltage controller in the grid-connected inverter is implemented using the PI control as

$$
i_{q i}^{*}=-\left(k_{p v}+\frac{k_{i v}}{s}\right)\left(V_{D C}^{*}-V_{D C}\right)
$$

where $V_{D C}$ is the DC link voltage, and $k_{p v}$ and $k_{i v}$ represent the proportional and integral gains of the voltage controller, respectively. In general, the current control loop which belongs to the primary control is responsible for the quality of the exchanging power. With (9) and the current reference of $i_{d i}^{*}=0$, the current controller is achieved using the PI decoupling control law on the synchronous reference frame as follows:

$$
\begin{aligned}
& v_{q i}^{*}=\left(k_{p i}+\frac{k_{i i}}{s}\right)\left(i_{q i}^{*}-i_{q i}\right)+\omega L i_{d i}+e_{2 q} \\
& v_{d i}^{*}=\left(k_{p i}+\frac{k_{i i}}{s}\right)\left(i_{d i}^{*}-i_{d i}\right)-\omega L i_{q i}+e_{2 d}
\end{aligned}
$$


where $k_{p i}$ and $k_{i i}$ represent the proportional and integral gains of the current controller in the grid-connected inverter, respectively.

\subsection{Interleaved Bidirectional DC-DC Converter}

Since the generated powers from different DG units are collected to the DC link bus in microgrid as shown in Figure 1, the ESS such as batteries and super-capacitor banks is connected to the DC Link through an interleaved bidirectional DC-DC converter. In microgrid, the ESS plays an important role of mitigating the power fluctuation from DG units as well as of enhancing the stability of entire power system.

Interleaved bidirectional DC-DC converter charges and discharges the ESS by controlling the battery current with constant level in either direction. Three-phase interleaved bidirectional DC-DC converter is shown in Figure 1. Since each phase is operated with phase shift of $120^{\circ}$ in this converter, the current ripples in each phase are cancelled out effectively. Thus, this converter has the advantages such as small current ripple, reduced system size, and higher power density as compared to single-phase one.

While the bidirectional DC-DC converter operates like a buck converter during charging mode operation of ESS, it operates like a boost converter during discharging mode operation depending on the SOC level, load demand, and generated power from WP system. Figure 2 shows the charging mode operation of interleaved bidirectional DC-DC converter when the switches are turned-on and -off, respectively, and Figure 3 shows the discharging mode operation when the switches are turned-on and -off, respectively. In the charging mode operation, to deliver the power either from the grid or DG units to battery, DC-DC converter operates as a buck converter. In this case, the upper switches are used as active switches while the lower switches as diodes as shown in Figure 2. On the other hand, to deliver the power from battery to the grid or local load, DC-DC converter operates as a boost converter, where the lower switches are used as active switches while the upper switches as diodes as shown in Figure 3.

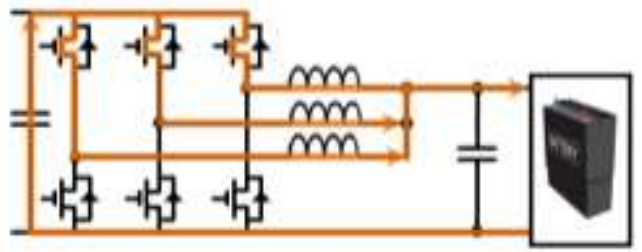

(a)

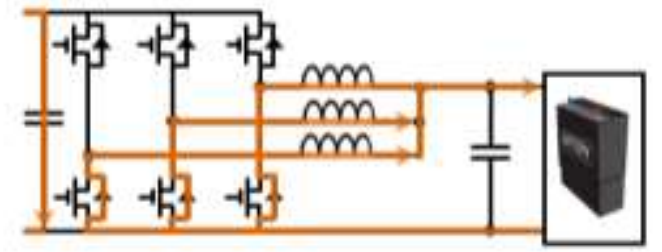

(b)

Figure 2. Charging Mode Operation of Bidirectional DC-DC Converter (Buck Mode): (a) Upper Switch On; and (b) Upper Switch Off

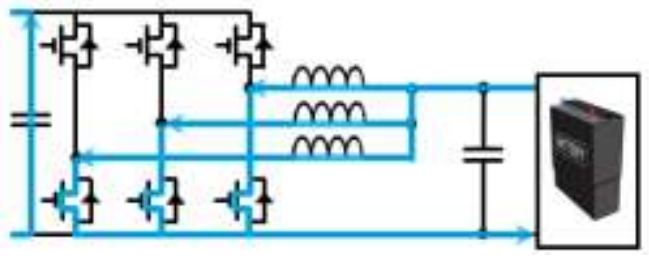

(a)

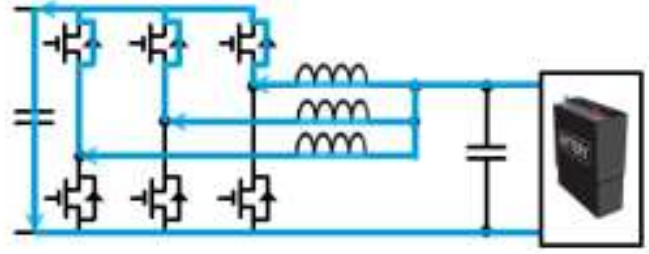

(b)

Figure 3. Discharging Mode Operation of Bidirectional DC-DC Converter (Boost Mode): (a) Low Switch On; and (b) Low Switch Off 


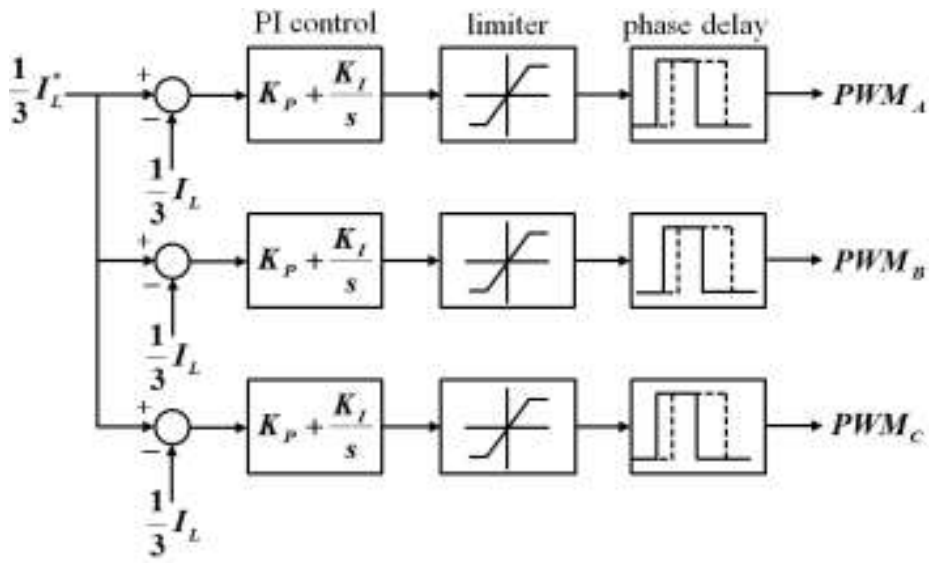

Figure 4. Current Control Scheme of Interleaved Bidirectional DC-DC Converter

To control the charging/discharging current of battery, the PI controller is employed as shown in Figure 4. As mentioned in Introduction, microgrid can operate in both gridconnected and islanded mode. In grid-connected mode, the DC link voltage control is achieved by the grid-connected inverter. On the contrary, during islanded mode where the main grid is absent due to grid fault, bidirectional DC-DC converter should control the DC link voltage. Figure 5 shows the DC link voltage control scheme by interleaved bidirectional DC-DC converter, where the output of the PI controller is the charging/ discharging current reference of battery.

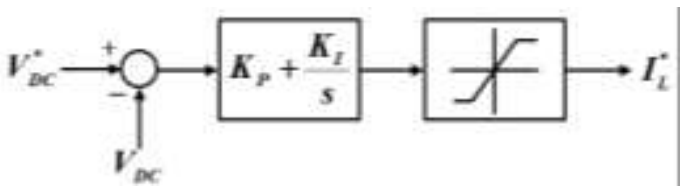

Figure 5. DC Link Voltage Control Scheme by Interleaved Bidirectional DCDC Converter Under Islanded Mode

\section{Operation Modes and Autonomous Control of AC Microgrid}

In this section, a cooperative and autonomous control strategy of $\mathrm{AC}$ microgrid is discussed both in grid-connected and islanded mode. Figure 6 shows the operation algorithm of microgrid connected with a WP system and ESS considered in this paper. According to the SOC level of battery, the generated power from DG unit, and the power demand of load, the operation mode of microgrid in the proposed scheme is classified as eight operating modes. These eight operating modes are mainly divided as grid-connected or islanded mode depending on the presence or absence of grid voltage. In Figure 6, the operating mode 1 through 5 corresponds to grid-connected mode, while the others to islanded mode. 


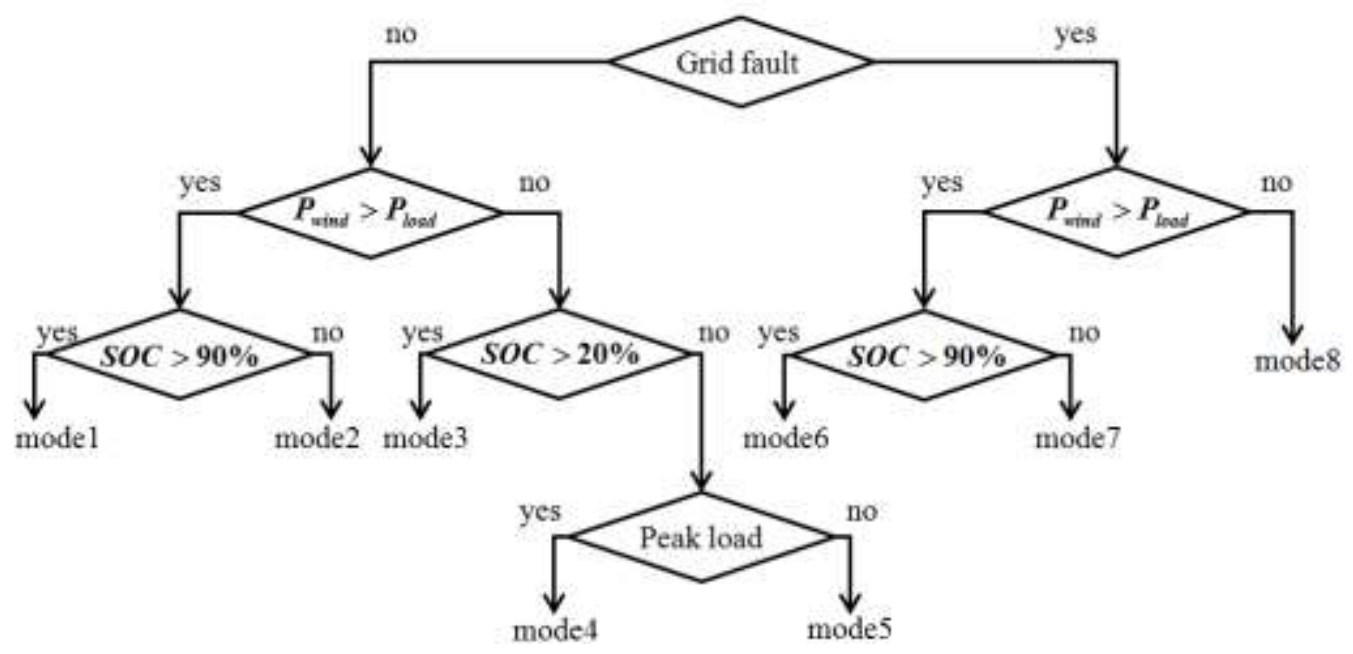

Figure 6. Operation Algorithm of Microgrid Connected with WP System and ESS

When microgrid is operated in grid-connected mode (mode 1 through 5) with interconnection to grid, the DC link voltage is controlled by the grid-connected inverter using (9). In these cases, the SOC level of battery and power demand of load determine the charge and discharge status of ESS through the bidirectional DC-DC converter. For example, if the developed power from WP system $P_{\text {wind }}$ is sufficiently larger than the power demand of load $P_{\text {load }}$, the operation mode of microgrid is determined according to the SOC level. If the SOC of battery is above $90 \%$, microgrid is operated with mode 1 to deliver the power to grid and local loads from the WP system as well as ESS through the bidirectional DC-DC converter and grid-connected inverter. Figure 7 shows the power flow diagram of mode 1 .

On the contrary, if the condition of $P_{\text {wind }}>P_{\text {load }}$ and SOC $<90 \%$ holds, the operation becomes mode 2 to deliver the power from the WP system to grid, local loads, and ESS at the same time as shown in the power flow diagram in Figure 8.

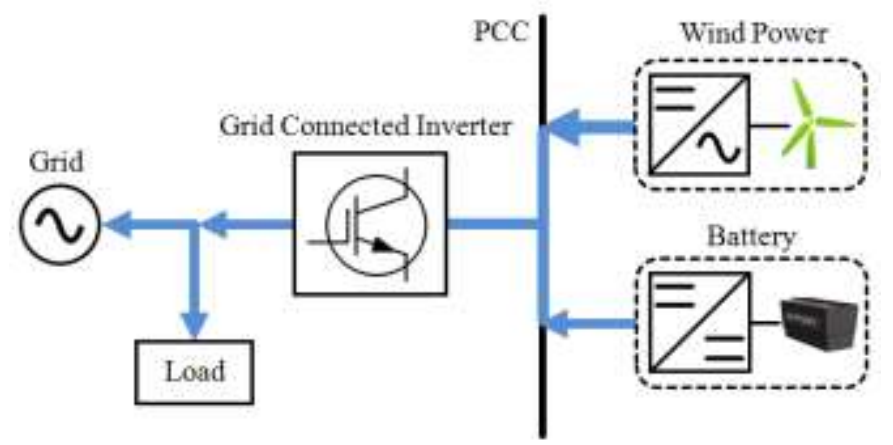

Figure 7. Power Flow Diagram in Mode 1 


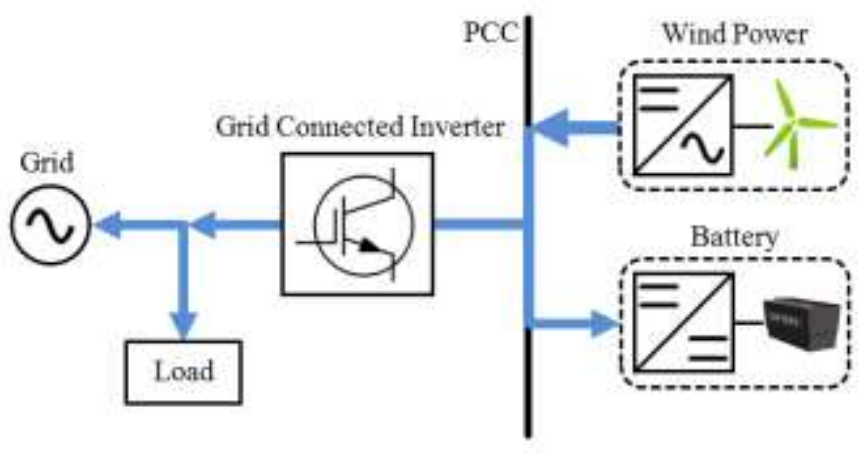

Figure 8. Power Flow Diagram in Mode 2

Under the condition $P_{\text {wind }}<P_{\text {load }}$, microgrid operation becomes mode 3, 4, and 5. In mode 3, if SOC $>20 \%$, the generated power from WP system together with ESS and grid supply the power to local load as shown in the power flow diagram in Figure 9.

If the ESS has a very low SOC level, the operation is determined according to load demand. At peak load period, DG unit and grid supply the local load without charging or discharging the ESS. This operation corresponds to mode 4 of which Figure 10 represents the power flow diagram. For off-peak period of load, microgrid is operated with mode 5 where DG unit and grid supply the local load and charge the ESS at the same time. The power flow diagram in this case is shown in Figure 11.

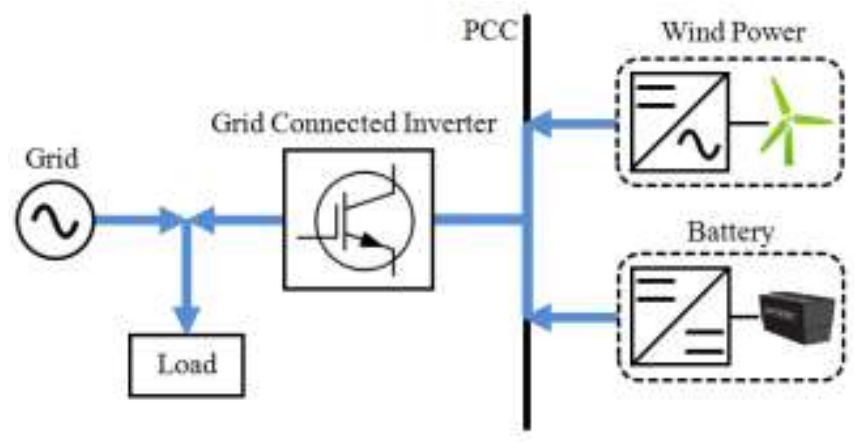

Figure 9. Power Flow Diagram in Mode 3

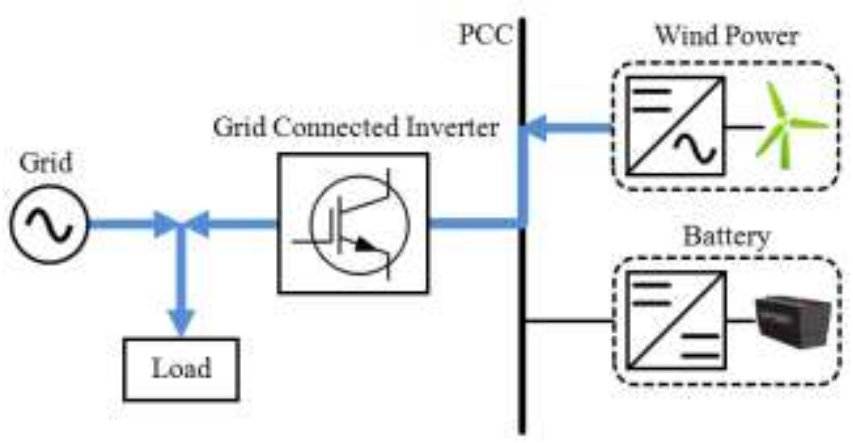

Figure 10. Power Flow Diagram in Mode 4 


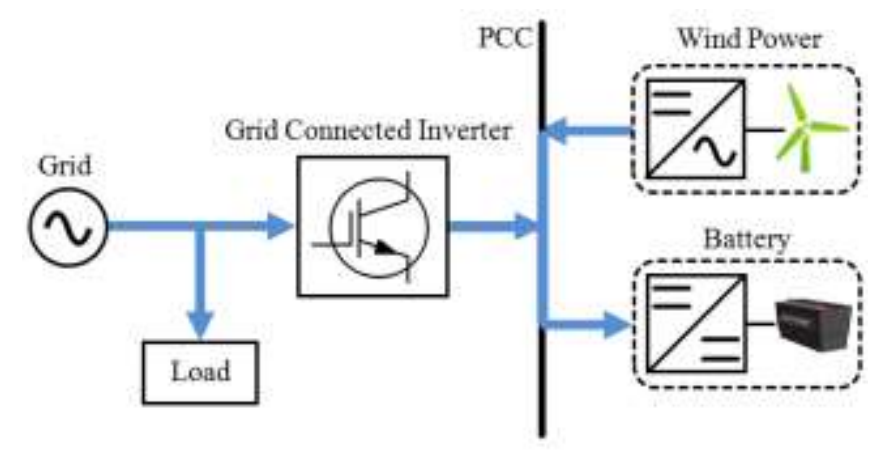

Figure 11. Power Flow Diagram in Mode 5

When microgrid is operated in islanded mode due to the absence of grid voltage, the DC link voltage is controlled by the interleaved bidirectional DC-DC converter as in Figure 5. The PI control algorithm is employed to support the DC link voltage where the output of the PI controller is the charging/discharging current reference of battery. On the other hand, the grid-connected inverter controls three-phase output voltages to supply the local loads in this mode. In this case, microgrid is composed of DG units, ESS, and local loads without the connection to grid, and the operation is divided into mode 6,7 , and 8 according to the developed power from DG unit, battery SOC level, and power demand of load.

Figure 12 shows the power flow diagram in mode 6 . The operation mode 6 occurs under the condition of $P_{\text {wind }}>P_{\text {load }}$ and SOC $>90 \%$. In this condition, the generated power from WP system is sufficient to supply the local loads without ESS, $P_{\text {wind }}$ alone supplies the load by adjusting the power generation of WP. If the battery SOC level is less than $90 \%$, the operation is changed to mode 7 . In this operating mode, the generated power from WP system supplies the local loads and the excessive power is used to charge ESS at the same time. The power flow diagram in mode 7 is shown in Figure 13.

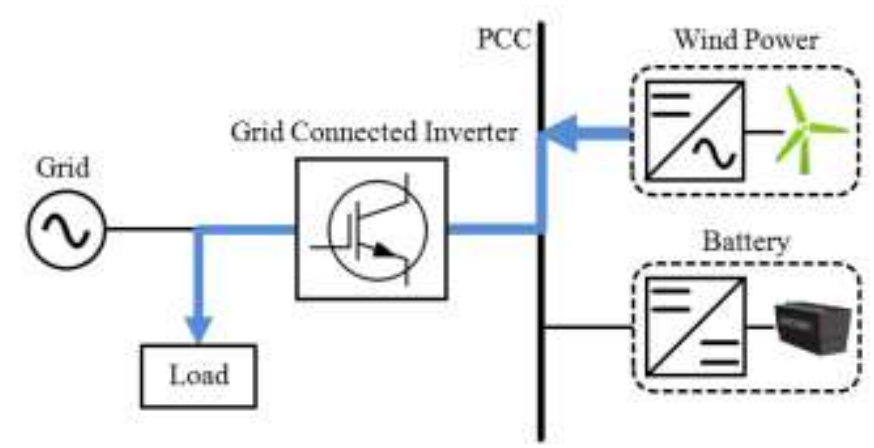

Figure 12. Power Flow Diagram in Mode 6 


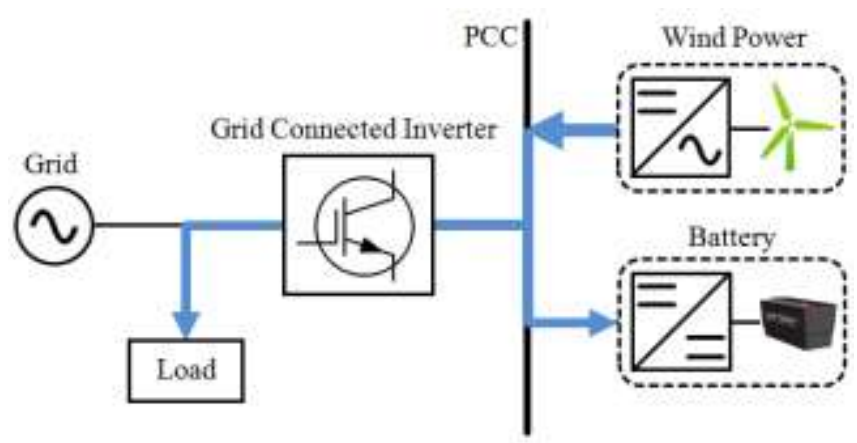

Figure 13. Power Flow Diagram in Mode 7

The last operating mode is mode 8 of Figure 6. This mode occurs when the generated power from WP system is less than the power requirement of load, that is, $P_{\text {wind }}<P_{\text {load }}$. In this condition, all available power is delivered to the local loads to supply load regardless of battery SOC level as shown in Figure 14.

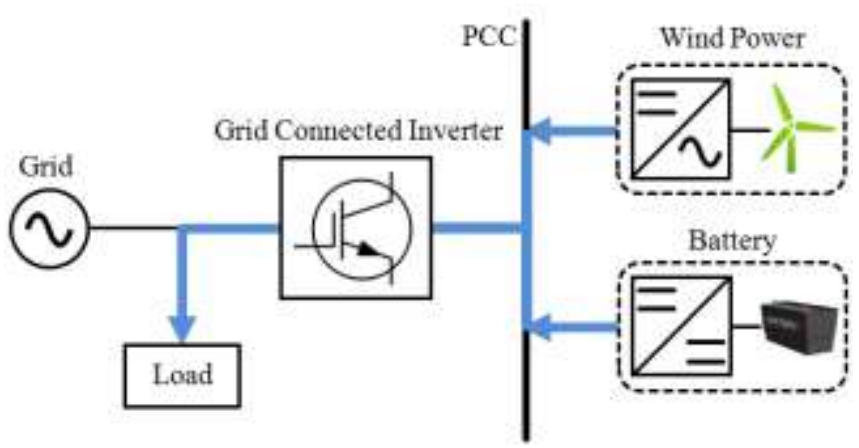

Figure 14. Power Flow Diagram in Mode 8

\section{Simulation Results}

To evaluate the performance of the proposed cooperative and autonomous control strategy of AC microgrid, the integrated simulation studies have been carried out. The entire simulation is done using the PSIM software where microgrid is connected as shown in Figure 1. To implement such a configuration, five PSIM DLL blocks are used for the main controllers as well as DG units as follows:

- DLL block 1: Control implementation for three-phase voltage source converter

- DLL block 2: Control implementation three-phase grid-connected inverter

- DLL block 3: Control implementation of interleaved bidirectional DC-DC converter

- DLL block 4: Implementation of wind turbine

- DLL block 5: Implementation of battery model.

A WP system is realized based on the PMSG-based variable-speed system. For a current control algorithm in the converter and inverter, the synchronous frame PI decoupling control is used with the sampling period of $100 \mu \mathrm{sec}$. To apply the computed reference voltages to both the converter and inverter, the symmetrical space vector PWM technique is employed. Figure 15 shows the simulation configuration of microgrid implemented based on the PSIM.

Figure 16 through Figure 19 shows the simulation results representing microgrid operation for each mode 1 through mode 8 . For the DC link voltage reference, $V_{D C}^{*}=600$ 
$\mathrm{V}$ is chosen where the DC link voltage control is achieved by the grid-connected inverter in grid-connected mode or by the interleaved bidirectional DC-DC converter in islanded mode. In all the figures, waveforms represent the output currents of grid-connected inverter $\left(i_{a}, i_{b}\right.$, and $\left.i_{c}\right)$, the output current of bidirectional DC-DC converter $\left(i_{\text {Battery }}\right)$, the DC link voltage $\left(V_{D C}\right.$ link $)$, and battery SOC value $\left(S O C_{\text {Battery }}\right)$, from the top. Figure 16 shows the simulation results for operating mode 1 and operating mode 2 , respectively. It is shown that the DC link voltage is well regulated to $600 \mathrm{~V}$. As shown in Figure 7 and Figure 8 , the power flow in these two cases is similar with the exception of battery charging/discharging current according to the SOC level. While the battery current is regulated to $-5 \mathrm{~A}$ to discharge the battery in operating mode 1 of Figure 16(a), it is regulated to $+5 \mathrm{~A}$ to charge the battery in operating mode 2 of Figure 16(b). It is confirmed from these figures that the charging and discharging operation of ESS is performed properly according to microgrid operation algorithm suggested in Figure 6.

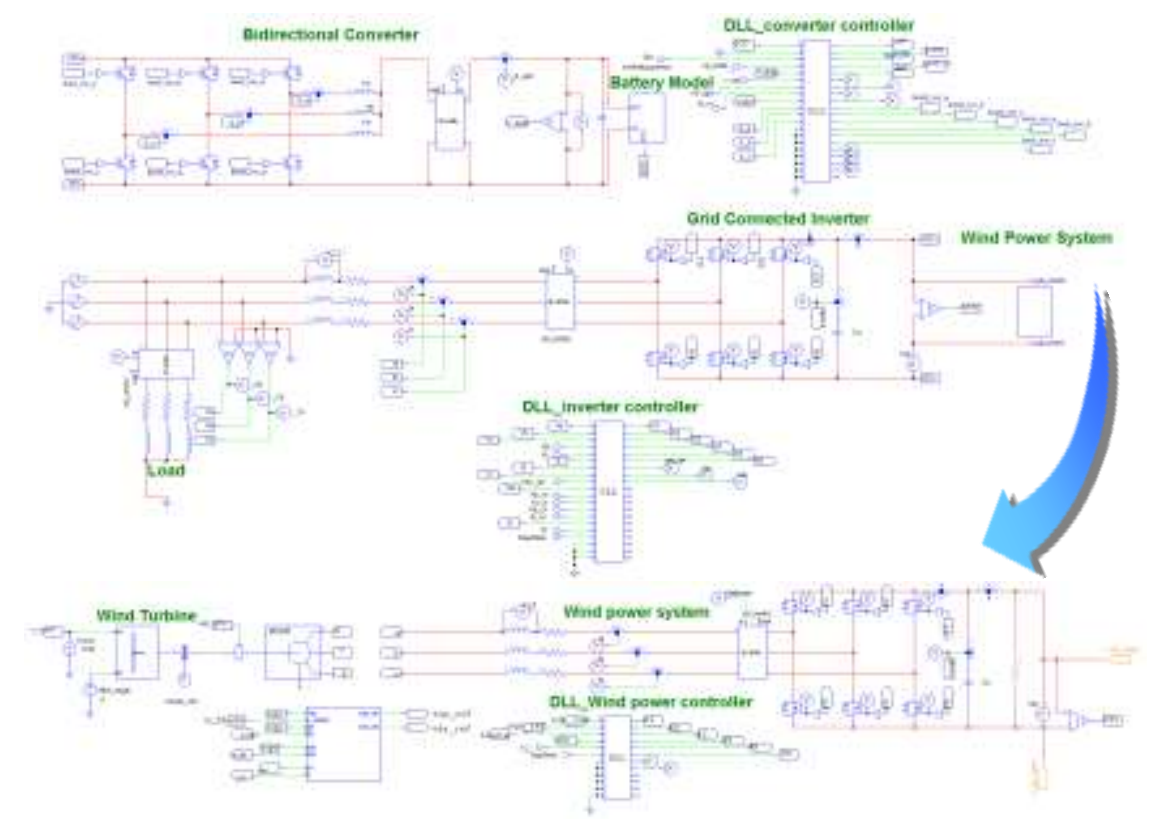

Figure 15. Simulation Configuration of Microgrid Based on PSIM

Figure 17 shows the simulation results for operating mode 3 and operating mode 4, respectively. In these modes, the power generated by the WP system is less than the load requirement. Thus, the grid should supply the local loads with the aid of both DG unit and ESS in mode 3, where the battery is operated in discharging mode with the battery current of $-5 \mathrm{~A}$. On the other hand, in mode 4 , the battery is not charged and discharged because it has low level of SOC at peak load period. This is due to the fact that the cost of electricity is generally high during peak load periods. In this mode, the proposed control strategy of microgrid decides to stop charging the battery immediately in order to reduce the power from the grid for load supply. As a result, the battery current $\left(i_{\text {Battery }}\right)$ is maintained to zero as seen in Figure 17(b).

Figure 18(a) shows the simulation results for operating mode 5. This mode has a similar power flow with the operating mode 4 in Figure 17(b) with only the exception that this mode occurs only during off-peak period of load. During this period, the battery can be charged with lower cost of electricity. Thus, the battery current is controlled to $+5 \mathrm{~A}$ to charge the battery as shown in Figure 18(a). 

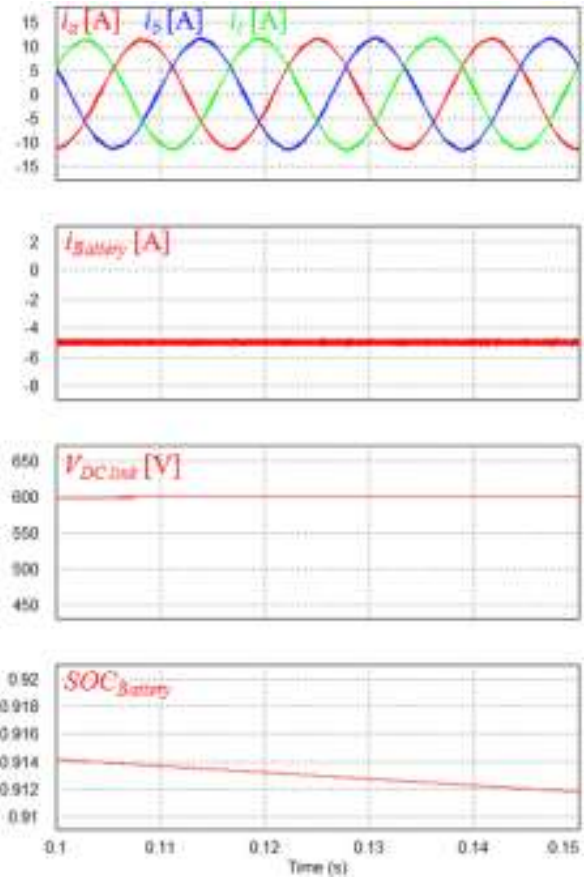

(a)
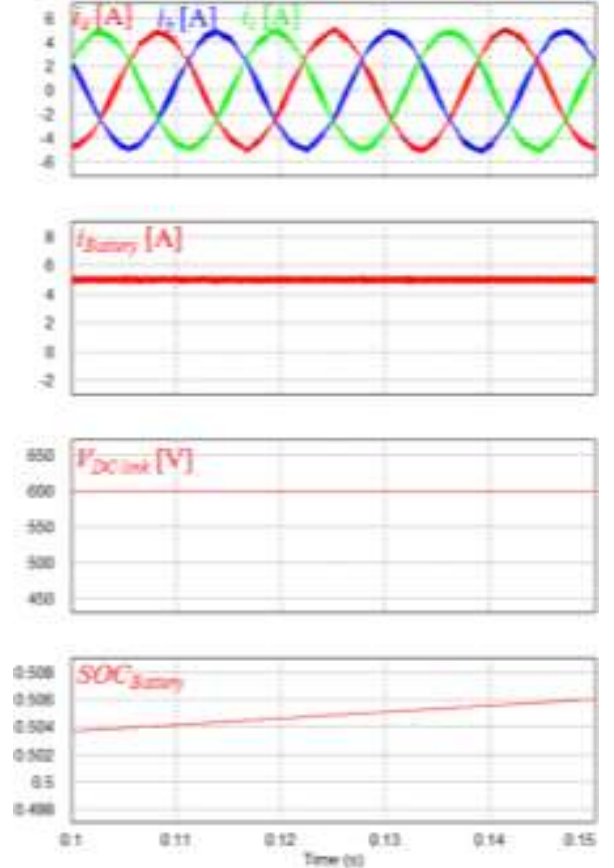

(b)

Figure 16. Simulation Results: (a) Operating Mode 1; and (b) Operating Mode 2
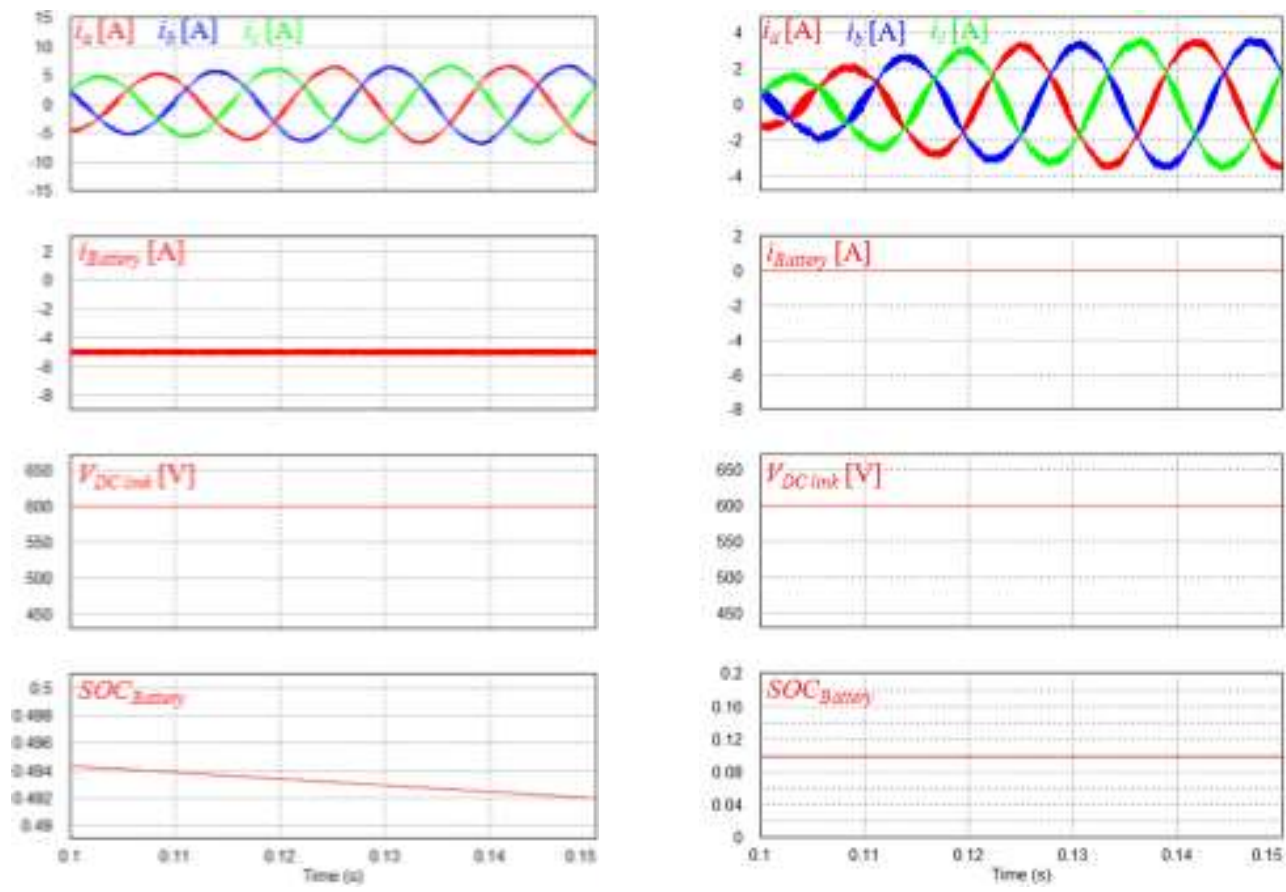

(a)

(b)

Figure 17. Simulation Results: (a) Operating Mode 3; and (b) Operating Mode 4

Figure 18(b) and Figure 19 show the simulation results for operating mode 6, 7, and 8, which correspond to the islanded mode due to the absence of grid voltages. In these modes, while the interleaved bidirectional DC-DC converter support the DC link voltage by charging/discharging the battery, the grid-connected inverter controls three-phase 
output voltages to supply the local loads continuously. Even in these cases, it is shown that the DC link voltage is well regulated to $600 \mathrm{~V}$. When the condition of $P_{\text {wind }}>P_{\text {load }}$ and SOC $>90 \%$ is satisfied, microgrid operation is determined as mode 6 with the power flow diagram as shown in Figure 12. Figure 18(b) shows the simulation results for this case. Since the battery is in sufficiently charged state, the battery is not charged and discharged $\left(i_{\text {Battery }}=0\right)$ and the developed power by DG unit only supplies the local loads by adjusting the amount of WP generation. Figure 19(a) shows the simulation results for operating mode 7 under the condition of $P_{\text {wind }}>P_{\text {load }}$ and SOC $<90 \%$. As is shown, it is observed that the developed power by DG unit supplies the power to the local loads and battery at the same time. Figure 19(b) shows the simulation results for operating mode 8 under the condition of $P_{\text {wind }}<P_{\text {load }}$. In this condition, the batter is discharged regardless of battery SOC value, to deliver all available power within microgrid to the local loads.
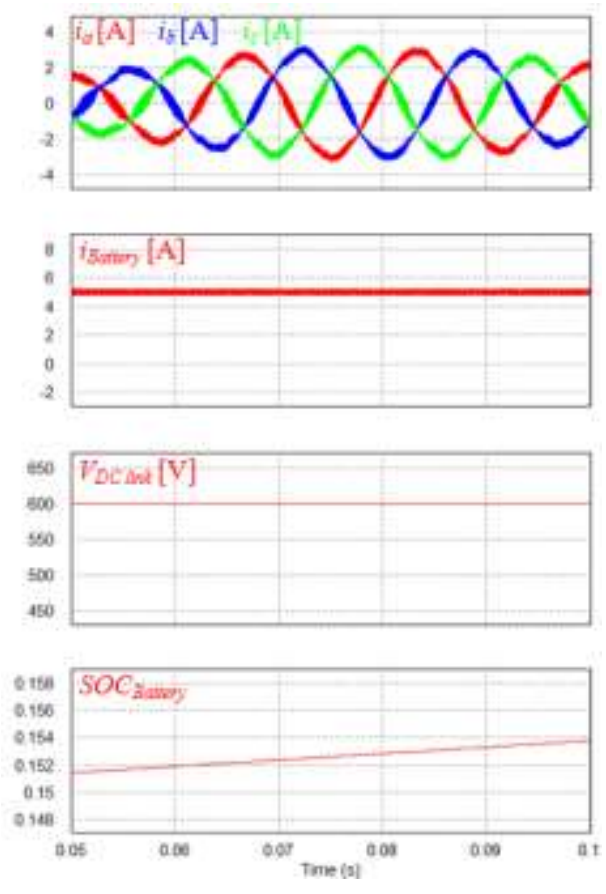

(a)
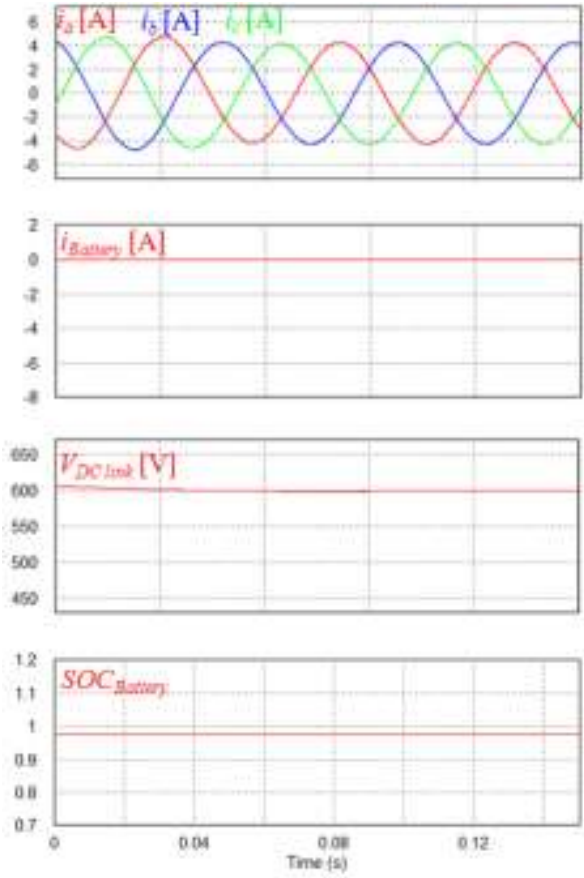

(b)

Figure 18. Simulation Results: (a) Operating Mode 5; and (b) Operating Mode 6 

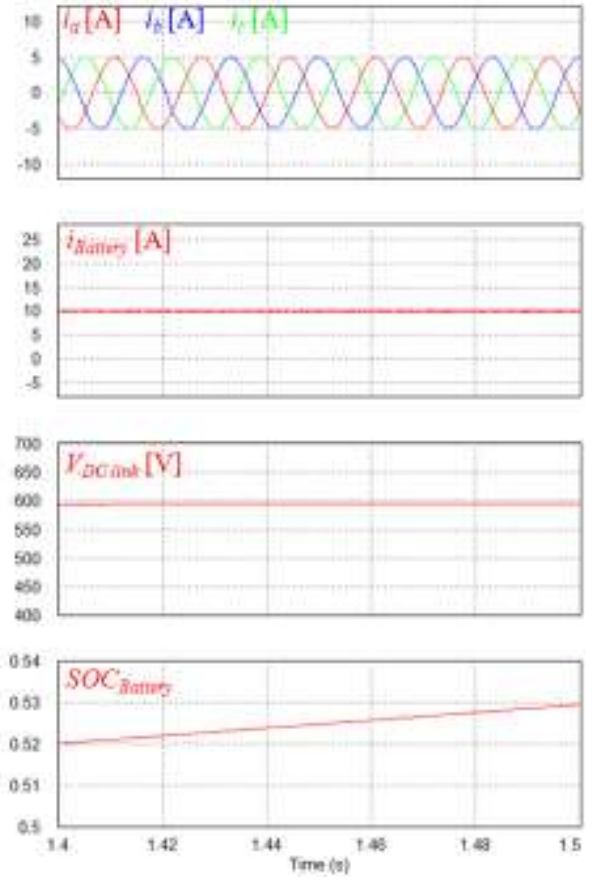

(a)
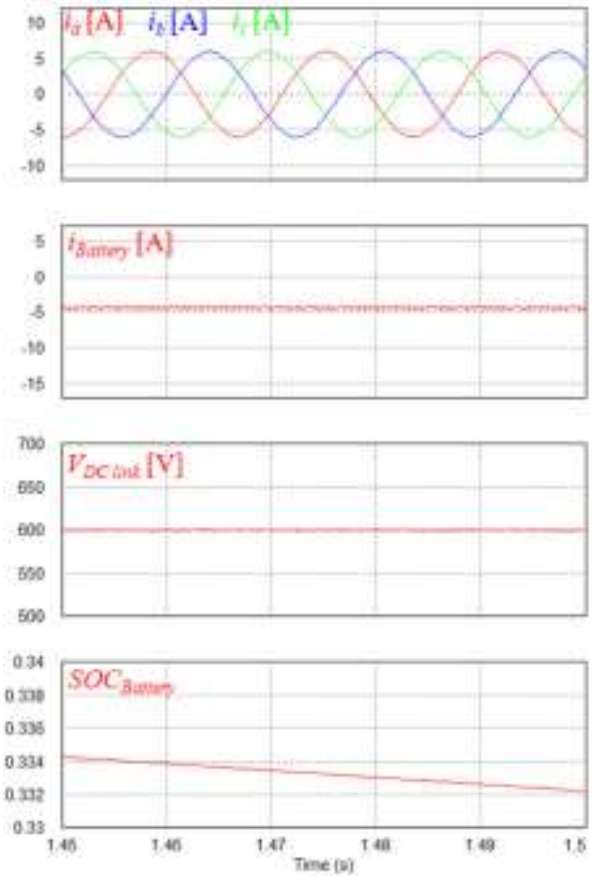

(b)

Figure 19. Simulation Results: (a) Operating Mode 7; and (b) Operating Mode 8

\section{Conclusions}

In this paper, to improve the flexibility and reliability of microgrid, a cooperative and autonomous control strategy of AC microgrid which consists of DG unit and ESS has been presented either in grid-connected or islanded mode. Microgrid operation strategy and the power flow within microgrid are determined by considering the generated power from DG unit, the power demand of load, and the ESS status. The entire microgrid operation algorithm consists of eight operating modes in which the power flow within microgrid and the control methods for power electronic converters are presented in details. By using the proposed control strategy, microgrid can autonomously and reliably change the operation mode in accordance with the power supply and load demand as well as ESS status. In a grid-connected mode, the proposed strategy enables microgrid to control the active and reactive powers into grid by maintaining the synchronization to grid. Furthermore, even in an islanded mode, microgrid is capable of supplying the power to local loads continuously. To verify the feasibility of the proposed microgrid operation strategy through integrated simulation studies, PSIM-based simulation model has been developed by taking into account a PMSG-based WP generation system and a lithium-ion battery. In addition, for power conversion in microgrid, the model of power electronic interfaces such as three-phase converter, a grid-connected inverter, and bidirectional DCDC converter has been implemented. Simulations results have been presented under various operating conditions to verify the validity of the proposed strategy. As a result, the proposed microgrid operation algorithm is very useful to construct cooperative and autonomous microgrid, which considerably contributes to improve the flexibility and reliability of the electrical power system. 


\section{Acknowledgements}

This research was supported by Basic Science Research Program through the National Research Foundation of Korea (NRF) funded by the Ministry of Education (NRF2016R1D1A1B03930975).

\section{References}

[1] T. L. Vandoorn, J. C. Vasquez, J. De Kooning, J. M. Guerrero, and L. Vandevelde, "Microgrids: Hierarchical control and an overview of the control and reserve management strategies," IEEE Industrial Electronics Magazine, vol. 7, no. 4, (2013), pp. 42-55.

[2] J. Y. Kim, J. H. Jeon, S. K. Kim, C. Cho, J. H. Park, H. M. Kim, and K. Y. Nam, "Cooperative control strategy of energy storage system and microsources for stabilizing the microgrid during islanded operation," IEEE Transactions on Power Electronics, vol. 25, no. 12 (2010), pp. 3037-3048.

[3] R. Zamora and A. K. Srivastava, "Controls for microgrids with storage: Review, challenges, and research needs," Renewable and Sustainable Energy Reviews, vol. 14, no. 7, (2010), pp. 2009-2018.

[4] J. M. Guerrero, J. C. Vasquez, J. Matas, L. G. De Vicuña, and M. Castilla, "Hierarchical control of droop-controlled AC and DC microgrids - A general approach toward standardization," IEEE Transactions on Industrial Electronics, vol. 58, no. 1, (2011), pp. 158-172.

[5] P. Paolo and L. Robert, "Autonomous control of microgrids," IEEE Power Eng. Soc. Meeting, Montreal, Canada, (2006), pp. 18-22.

[6] J. Eyer and G. Corey, "Energy storage for the electricity grid, Benefits and market potential assessment guide," Sandia National Laboratories, vol. 20, no. 10 (2010), pp. 5.

[7] C. Gouveia, C. L. Moreira, J. A. P. Lopes, D. Varajao, and R. E. Araujo, "Microgrid service restoration The role of plugged-in electric vehicles," IEEE Industrial Electronics Magazine, vol. 7, no. 4, (2013), pp. 26-41.

[8] W. Lee, B. M. Han, and H. Cha, "Battery ripple current reduction in a three-phase interleaved dc-dc converter for 5kW battery charger," 2011 IEEE Energy Conversion Congress and Exposition. IEEE, (2011), pp. 3535-3540.

[9] K. C. Divya and J. Østergaard, "Battery energy storage technology for power systems - An overview," Electric Power Systems Research, vol. 79, no. 4, (2009), pp. 511-520.

[10] Q. Jiang, Y. Gong, and H. Wang, "A battery energy storage system dual-layer control strategy for mitigating wind farm fluctuations," IEEE Transactions on Power Systems, vol. 28, no. 3, (2013), pp. 3263-3273.

[11] J. Zhang, J. S. Lai, R. Y. Kim, and W. Yu, "High-power density design of a soft-switching high-power bidirectional dc-dc converter," IEEE Transactions on Power Electronics, vol. 22, no. 4, (2007), pp. 1145-1153.

[12] W. Zhang, D. Xu, X. Li, R. Xie, H. Li, D. Dong, and M. Chen, "Seamless transfer control strategy for fuel cell uninterruptible power supply system," IEEE transactions on power electronics, vol. 28, no. 2, (2013), pp. 717-729.

[13] K. H. Kim, "Performance investigation and observer-based condition monitoring scheme for a PMSGbased grid-connected wind power system under switch open fault," SERSC International Journal of Control and Automation, vol. 6, no. 4, (2013), pp. 483-498.

[14] P. C. Krause, Analysis of Electric Machinery, McGraw-Hill, New York (1986)

[15] R. C. Dorf and R. H. Bishop, Modern Control Systems, Prentice-Hall International Editions, (2005)

\section{Authors}

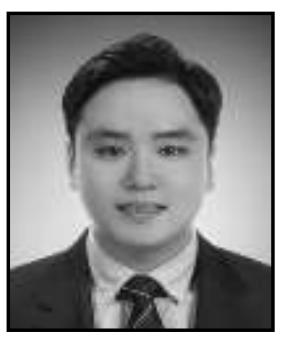

Myeong-Jun Jang, was born in Suwon, Korea, in 1989. He received the B.S degree in the Department of Electrical and Information Engineering at Seoul National University of Science and Technology, Seoul, Korea, in 2015. He is currently working toward the M.S. degree in the Department of Electrical and Information Engineering at Seoul National University of Science and Technology. His research interests include renewable energy, power electronics, energy storage system, microgrid, and DSP-based control applications. 


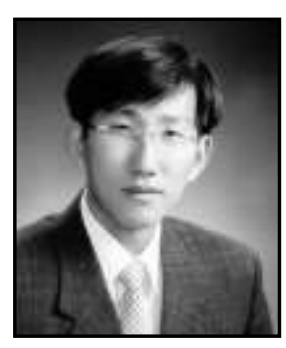

Kyeong-Hwa Kim, was born in Seoul, Korea, in 1969. He received his B.S. degree from Hanyang University, Seoul, Korea, in 1991; and his M.S. and Ph.D. degrees from the Korea Advanced Institute of Science and Technology (KAIST), Daejeon, Korea, in 1993 and 1998, respectively, all in Electrical Engineering. From 1998 to 2000, he was a Research Engineer with Samsung Electronics Company, Korea, where he was engaged in the research and development of AC machine drive systems. From 2000 to 2002, he was a Research Professor with KAIST. From August 2010 to August 2011, he was a Visiting Scholar with the Virginia Polytechnic Institute and State University (Virginia Tech), Blacksburg, VA, USA. Since August 2002, he has been with the Seoul National University of Science and Technology, Seoul, Korea, where he is presently working as a Professor. His current research interests include AC machine drives, the control and diagnosis of power systems, power electronics, renewable energy, and DSP-based control applications. Professor Kim is a Member of the Korean Institute of Power Electronics (KIPE) and IEEE. 
International Journal of Control and Automation

Vol. 10, No. 5 (2017) 